\title{
Valorisation of Mango Peels: Extraction of Pectin and Antioxidant and Antifungal Polyphenols
}

\author{
Romeo Rojas ${ }^{1}$. Olga B. Alvarez-Pérez ${ }^{1}$. Juan C. Contreras-Esquivel ${ }^{1} \cdot$ António Vicente $^{2} \cdot$ Abril Flores $^{2}$. \\ Jose Sandoval ${ }^{1} \cdot$ Cristobal N. Aguilar $^{1}$ (i)
}

Received: 23 January 2018 / Accepted: 22 August 2018 / Published online: 25 August 2018

(c) Springer Nature B.V. 2018

\begin{abstract}
Mango peels is a by-product obtained during mango processing, which is currently discarded causing environmental pollution. In the present study, mango peels were used as source of polyphenols and pectin. Additionally, antioxidant and antifungal activities were measured. The extraction condition to recover pectin and polyphenols at the same time was using water, $121{ }^{\circ} \mathrm{C} / 10 \mathrm{~min}$ at $1: 40 \mathrm{w} / \mathrm{v}$ ratio $(9.38 \mathrm{~g} / 100 \mathrm{~g}$ dry peels and $72.61 \mathrm{mg} / \mathrm{g}$ dry peels, respectively). With this treatment, higher antioxidant capacity was obtained $(72.18,37.73$ and $39.23 \mathrm{ppm}$ of total polyphenols from mango peels to inhibit 2,2-diphenyl-1-picrylhydrazyl and 2,2'-azino-bis(3-ethylbenzothiazoline-6-sulphonic acid) free radical; also the lipid oxidation inhibition reaction in 50\%, respectively). Furthermore, this extract inhibited the radial growth of Colletotrichum gloeosporioides, Sclerotinia sclerotiorum and Mucor sp. in 50\% and Fusarium oxysporum in $33.33 \%$. Thus, the results suggest that total polyphenols from mango peels is as attractive alternative source for bioactive compounds, like antioxidants and antifungal molecules.
\end{abstract}

Keywords Mango peels $\cdot$ Polyphenols $\cdot$ Antioxidant $\cdot$ Antifungal $\cdot$ Pectin

\section{Statement of Novelty}

Mango processing includes the production of juices, nectars, concentrates, jams, jelly powders, fruit bars, flakes, and dried fruit. However, by-products such as peels and kernel represent $24 \%$ and $40 \%$ of fresh fruit, respectively, generating an abundant quantity of wastes which represents an attractive source of value-added compounds. The present study describes an integrated alternative for the combined recovery of phenolic compounds and pectin from mango peels giving an attractive valorisation of this waste.

Cristobal N. Aguilar

cristobal.aguilar@uadec.edu.mx

1 Bioprocesses and Bioproducts Research Group (BBG-DIA). Food Research Department, School of Chemistry, Universidad Autónoma de Coahuila, 25280 Saltillo, Coahuila, Mexico

2 Centre of Biological Engineering, University of Minho, Campus de Gualtar, 4710-057 Braga, Portugal

\section{Introduction}

Mango Ataulfo (Mangifera indica L.) is one of the most appreciated fruits around the world by their sensorial and organoleptic properties, however, one of the most important problems of its commercialization is the short shelf life of this product. By this reason, mango is transformed in juices, nectars, concentrates, jams, jelly powders, fruit bars, flakes, and dried fruit [1]. However, by-products such as peels and kernel represent $24 \%$ and $40 \%$ of fresh fruit, respectively.

Mango kernels have been studied as a source of natural antioxidants, starch, flour, and feed [2-6], but studies on peels from Ataulfo variety are scarce. Some studies have been reported regarding their use to produce biogas [7, 8] or dietary fiber with antioxidant activity [9-11]. Other studies have been dealing with their use as a source of pectin [12-16]. The high quality of this product is due to the degree of esterification between 56 and 66\% [1]. Additionally, mango peels have been shown to be a rich source of compounds such as flavonol $O$ - and xanthone $C$-glycosides [1, 17], gallotannins and benzophenone derivates [18]. These compounds have antioxidant, antifungal, antiproliferative, 
anti-atherogenic, anti-thrombotic, and anti-inflammatory effects [19-30].

Nowadays, there are methodologies to recover bioactive compounds from agro industrial residues. However, these methodologies are specific and with only one purpose. Seeram et al. [31] and Ascasio-Valdés et al. [32] described methods to recovery total polyphenols from agroindustrial wastes using only water. Contreras-Esquivel et al. [33] described a method to extract pectin from mango peels using water and a citric acid solution with yields up to $39 \%$. However, the combination of both methodologies can be an alternative to recover pectin and total polyphenols from mango peels.

Earlier, our research group has published relevant information about the agroindustrial potential [34], the functional and nutritional properties [35] of mango, also, the microwave-assisted extraction optimization for antioxidative compounds [36] making emphasis in functional properties of pentagalloylglucose [37]. In the present study, we report a combined strategy methodology for the recovery of pectin and polyphenols from mango peels. Total polyphenols and pectin present in the mango peels were evaluated characterized and quantified. Finally, the antifungal activity of a richpolyphenols extracts against some phytopathogenic fungi was evaluated.

\section{Materials and Methods}

\section{Fruits}

A lot of 49 mangoes were acquired from the local market (Benito Juarez) of Saltillo, Coahuila, Mexico. Peels were removed with a stainless-steel knife and blanched with water vapor at $105{ }^{\circ} \mathrm{C} / 15 \mathrm{~min}$ to inactivate enzymes. Mango peels were dried in a circulating drying oven at $60{ }^{\circ} \mathrm{C}$ for $5 \mathrm{~h}$, until a drying loss of $80 \%$. After, dry peels were stored in black sealed polyethylene bags at room temperature until use.

\section{Extraction of Total Polyphenols}

Six methods to extract total polyphenols from mango peels (TPMP) were used. (1.1) and (1.2) were according to Seeram et al. [31] and Ascasio-Valdés et al. [32], dehydrated and pulverized mango peels were placed in a baker in a ratio of $0.20 \mathrm{~g} / \mathrm{mL}$. TPMP extraction was performed at $60{ }^{\circ} \mathrm{C} / 30 \mathrm{~min} .2 .1$ and 2.2 were carried out according to Contreras-Esquivel et al. [33], dehydrated and crashed mango peels were placed in an autoclave $\left(121^{\circ} \mathrm{C} / 10 \mathrm{~min}\right)$ in a ratio $1: 40 \mathrm{w} / \mathrm{v} .3 .1$ and 3.2 were evaluated, dehydrated and crushed mango peels were placed in an autoclave $\left(121{ }^{\circ} \mathrm{C} / 20 \mathrm{~min}\right)$ in a ratio $1: 40 \mathrm{w} / \mathrm{v}$. After that, the obtained extracts were centrifuged at $7000 \mathrm{rpm} / 30 \mathrm{~min}$ to eliminate insoluble-water particles. For each extract the pectin was precipitated with isopropanol. Column chromatography was performed using Amberlite XAD-16. First, water was used as the eluent to discard undesirable compounds, and then, ethanol was employed as the eluent to obtain a TPMP. The residual ethanol was eliminated placing the ethanolic fraction in glass Petri dishes at $60^{\circ} \mathrm{C} / 24 \mathrm{~h}$; the polyphenols were recovered as a fine powder and stored in an amber bottle at $-20{ }^{\circ} \mathrm{C}$ until use. (Fig. 1).

\section{Yield and Chemical Analysis}

Polyphenols yield was calculated gravimetrically. Total sugars were evaluated with the Dubois et al. [38] method. Hydrolysable tannins were evaluated with the Folin-Ciocalteau method $[39,40]$ and reported as gallic acid equivalents and condensed tannins quantified with the $\mathrm{HCl}-\mathrm{Butanol}$ method [41] using catechin as standard. Each analysis was performed in triplicate.

\section{Antioxidant Assay}

The total antioxidant activity of the extracts was tested by four different methods, namely, two different free radical scavenging assays [1,1-dipheny 1-2-picrylhydrazyl (DPPH) and 2,2-azino-bis(3-ethylbenzothiazoline-6-sulfonic acid) $\left(\mathrm{ABTS}^{+}\right)$radical inhibition], a oxidation inhibition assay using linoleic acid as the lipid source lipid and a voltammetric method.

\section{DPPH'-Scavenging Capacity (DSC) Assay}

The DPPH assay was carried out according to the methodology reported by Molyneux [42]. Briefly, $193 \mu \mathrm{L}$ of $60 \mu \mathrm{M}$ DPPH radical was added to $7 \mu \mathrm{L}$ of each sample in a microplate. The microplate was placed in the dark and after $30 \mathrm{~min}$ the absorbance (Abs) was measured at $517 \mathrm{~nm}$. Controls contained $7 \mu \mathrm{L}$ of distilled water. The evaluated concentrations were $0,20,40,60,80$ and $100 \mathrm{ppm}$ of polyphenols in distilled water. The radical-scavenging capacity of the extracts was calculated using the following Eq. (1) and expressed as the DPPH percentage of inhibition.

Inhibition $(\%)=\left[\left(A b s_{\text {control }}-A b s_{\text {sample }}\right) / A b s_{\text {control }}\right] \times 100$

\section{$\mathrm{ABTS}^{++}$-scavenging capacity (ASC) assay}

The $\mathrm{ABTS}^{+}$assay was carried out according to the methodology proposed by Re et al. [43]. For radical $\left(\mathrm{ABTS}^{+}\right)$ formation, $12.5 \mathrm{~mL}$ of $2.45 \mathrm{mM}$ potassium persulfate was mixed with $25 \mathrm{~mL}$ of a $7 \mathrm{mM}$ ABTS solution; the mixture 
Fig. 1 Processes 1 and 2 for the combined recovery of phenolic compounds and pectin from mango peels. *Amberlite XAD16 , **the aqueous effluent was discarded

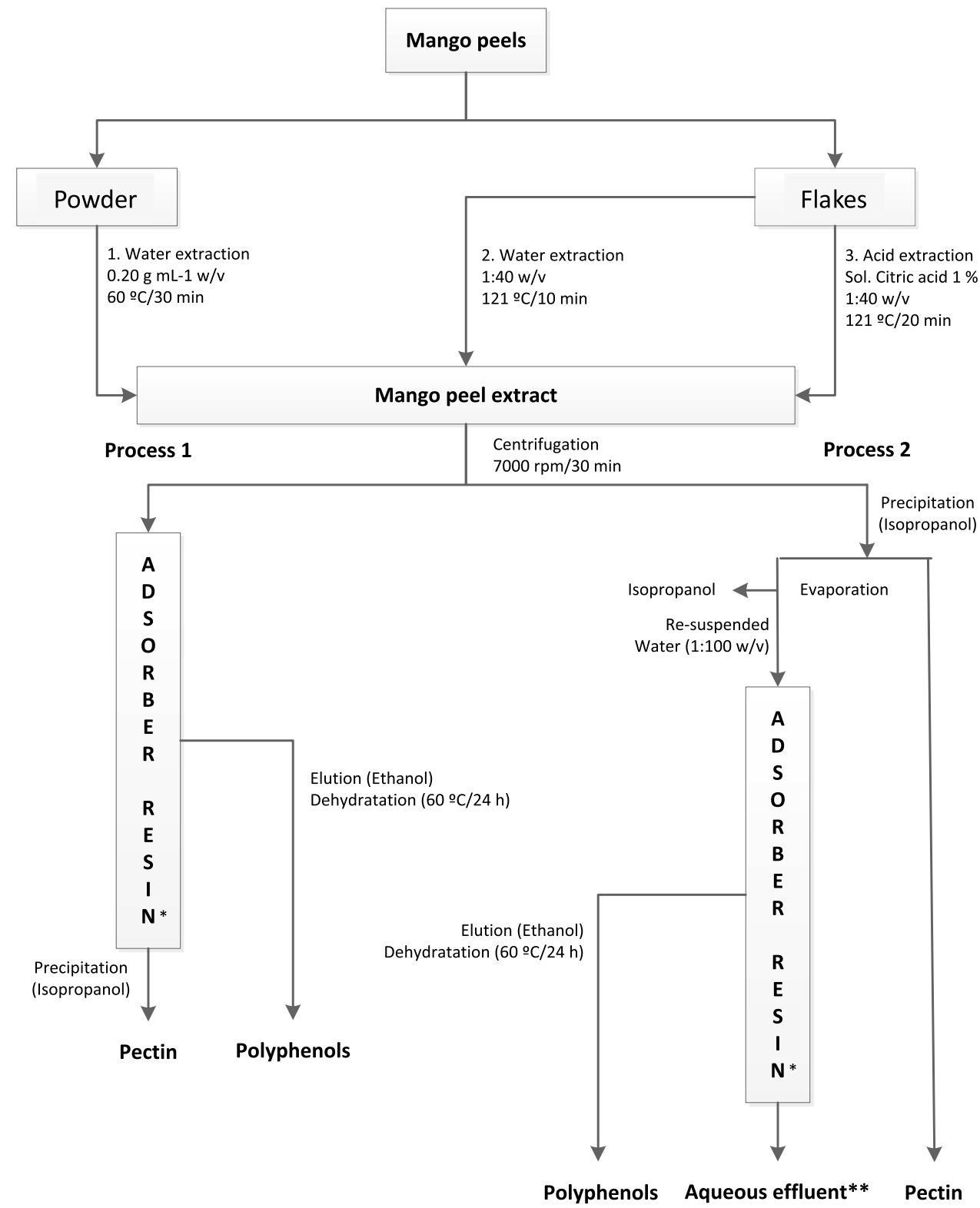

was then allowed to stand in the dark at room temperature for 12-16 h before use. Absorbance was measured at $734 \mathrm{~nm}$, and the $\mathrm{ABTS}^{+}$solution was diluted with ethanol until an absorbance value of $0.7 \pm 0.01$. For this study, $950 \mu \mathrm{L}$ of $\mathrm{ABTS}^{+}$adjusted solution was added to $50 \mu \mathrm{L}$ of each concentration of extract, and absorbance was measured immediately. Controls contained $50 \mu \mathrm{L}$ of distilled water. The evaluated concentrations were $0,20,40,60,80$ and $100 \mathrm{ppm}$ of polyphenols in distilled water. The radicalscavenging capacity of the extracts was calculated with the following Eq. (2) and expressed as the $\mathrm{ABTS}^{+}$percentage inhibition:

Inhibition $(\%)=\left[\left(A b s_{\text {control }}-A b s_{\text {sample }}\right) / A b s_{\text {control }}\right] \times 100$

\section{Lipid Oxidation Inhibition Assay}

The lipid oxidation inhibition (LOI) was performed using linoleic acid as the lipid source according to the method described by Starzynska-Janiszewska et al. [44] with slight modifications proposed by Martinez-Avila et al. [45]. The linoleic acid solution was prepared by diluting $0.56 \mathrm{~g}$ of linoleic acid and $1.5 \mathrm{~g}$ of Tween 20 in $8 \mathrm{~mL}$ of $96 \%$ ethanol. Each concentration of extract from Hojasen $(50 \mu \mathrm{L})$ was mixed with $100 \mu \mathrm{L}$ linoleic acid solution and $1.5 \mathrm{~mL}$ of $0.02 \mathrm{M}$ acetate buffer, $\mathrm{pH} 4$. Controls contained $50 \mu \mathrm{L}$ of distilled water. All samples were homogenized in a vortex (Velp® Scientifica $\mathrm{Zx}^{3}$ ) and sonicated in ultrasonic bath (Bransonic 2510R-MTH; Banson, Danbury, CT) for $3 \mathrm{~min}$. Obtained emulsions were incubated at $37^{\circ} \mathrm{C}$ (Yamato IC 
400); after, $1 \mathrm{~min}, 750 \mu \mathrm{L}$ of $50 \mathrm{M} \mathrm{FeCl}_{2}$ solution were added to induce the oxidation of linoleic acid. After the chosen incubation times ( 1 and $24 \mathrm{~h}$ ), $1 \mathrm{~mL}$ of $0.1 \mathrm{M} \mathrm{NaOH}$ in $10 \%$ ethanol was added to $250 \mu \mathrm{L}$ of the mixture to stop the oxidation process. After mixing, $2.5 \mathrm{~mL}$ of $10 \%$ ethanol was added and the absorbance measured at $232 \mathrm{~nm}$ against a $10 \%$ ethanol blank. The evaluated concentrations were $0,20,40$, 60, 80 and 100 ppm of polyphenols in distilled water. The percentage of antioxidant capacity was calculated according to the Eq. (3):

Inhibition $(\%)=(A-B / A) \times 100$

where " $\mathrm{A}$ " is the difference between the absorbance of the control sample after 24 and 1 of incubation, and " $\mathrm{B}$ " is the difference between the absorbance of each concentration sample after $24 \mathrm{~h}$.

\section{Electrochemical Assay}

Experiments were performed in the cyclic voltammetry (CV) and differential pulse voltammetry (VDP). These techniques are based on the oxidation or reduction of an electroactive compound at the working electrode while a constant potential is applied; the measured current in $\mathrm{nA}$ is a direct measurement of the electrochemical reaction rate. The $\mathrm{CV}$ and VDP were performed in a potentiostat/galvanostat basic Epsilon, the electrochemical cell consisted of three electrodes: working platinum electrode, coiled platinum electrode as a counter electrode and a silver-silver chloride (Ag/ $\mathrm{AgCl}$ ) electrode as a reference to the potential. Before the tests are performed a routine sweep using cyclic voltammetry for the reaction of $\mathrm{Fe}^{3+} / \mathrm{Fe}^{2+}$ is performed for the characterization of the platinum electrode; after this, the electrode was washed with water. Analyses were performed at room temperature using a carrier solution made of acetate buffer $0.1 \mathrm{M}$ (pH 5). Electrochemical evaluation of the antioxidant power of TPMP extracted with method 2.2 at a concentration of $39.23 \mathrm{ppm}$ were evaluated by measuring the current resulting from the oxidation of the electroactive compound at the established potential in the range of 100 to $900 \mathrm{mV}$.

\section{Antifungal Activity}

Four microorganisms (Colletotrichum gloeosporioides, Fusarium oxysporum, Sclerotinia sclerotiorum and Mucor sp.) were provided by the Food Research Department of the School of Chemistry (Autonomous University of Coahuila). Microorganisms were activated in PDA medium by 7 days at $28 \pm 2{ }^{\circ} \mathrm{C}$. To determine minimum inhibition concentration $\left(\mathrm{MIC}_{50}\right)$ PDA medium (previously sterilized) was supplemented with PTMP at concentrations of 0 (control without PTMP), 150, 300, 450, 750, 1000 and 1250 ppm (w/v). After that, an explant of $0.5 \mathrm{~cm}$ of diameter of each microorganism was placed in the centre of the petri dish. Radial growth was measured at final time of incubation at $28 \pm 2{ }^{\circ} \mathrm{C}(72 \mathrm{~h}$ to Colletotrichum gloeosporioides and $F$. oxysporum and $48 \mathrm{~h}$ to $S$. sclerotiorum and Mucor sp.). The mycelial growth of the control was considered as $100 \%$ growth, percent inhibition was calculated with Eq. (4).

Inhibition $(\%)=\left(\frac{m m \text { Growth }_{\text {control }}-m m \text { Growth }_{\text {sample }}}{m m \text { Growth }}\right) \times 100$

After that, dates were adjusted to a polynomial equation to determine the minimum inhibition concentration $\left(\mathrm{MIC}_{50}\right)$.

\section{Statistical Analysis}

For DPPH, $\mathrm{ABTS}^{+}$, and lipid oxidation inhibition assay, the measurements were made in triplicate. To determine the medium concentration inhibition $\left(\mathrm{MCI}_{50}\right)$ was used a simple linear regression to obtain the line equation $(y=m x+b)$ where " $y$ " is the percentage of inhibition (50\% in all cases), " $m$ " is the slope of the line, " $x$ " is the mg of TPMP to inhibit in $50 \%$ the oxidation reaction and " $b$ " is the intercept. In the case of antifungal activity to determine medium concentration inhibition $\left(\mathrm{MIC}_{50}\right)$ was employed a polynomial equation $\left(y=a x^{3}+b x^{2}+c x+d\right)$ where " $x$ " is the mg of TPMP to inhibit in $50 \%$ the fungal growth. Finally, a selection index (S-I) was used to determine the best treatment to obtain pectin and polyphenols at the same time. The following Eq. (5) was used to consider by relevance the analysis used:

$$
\begin{aligned}
& S-I=(P \times 2)+(Y \times 2)+(T \times 1)+(H \times 2) \\
& \quad+(C \times 0.5)+(D \times 0.5)+(A \times 0.5)+(L \times 1.5)
\end{aligned}
$$

where " $P$ " is the pectin yield; " $Y$ " is the yield of TPMP; " $T$ " is the total sugars of TPMP; " $H$ " is the hydrolysable tannins of TPMP; " $C$ " is the condensed tannins of TPMP; " $D$ " is the DPPH activity of TPMP; " $A$ " is the ABTS activity of TPMP and " $L$ " is the lipid oxidation inhibition of TPMP. The best treatment was used to determine antifungal activity and electrochemical assay. The results were analyzed using a completely randomized design and the means were compared with Tukey test at a confidence level of 0.95 .

\section{Results and Discussion}

Mango var. Ataulfo fruit is a Mexican variety and its waste (peels) is an underestimated source of polyphenols with higher antioxidant and antifungal capacities. The selection of this fruit was based on the seasonal production period 
(March-June), its present importance in Mexico and the limited or no information about its functional properties.

\section{Chemical Analysis}

The pectin yield and chemical analysis of TPMP is shown in Table 1. The mango peels had a pectin yield in the range of 3.33-16.01 g/100 g dry peels. Sirisakulwat et al. [46] reported a yield of pectin from mango peels $(25-42 \mathrm{~g} / 100 \mathrm{~g})$, however, with Tai mango using $\mathrm{H}_{2} \mathrm{SO}_{4} 1 \mathrm{~mol} / \mathrm{L}$ and lasts $1 \mathrm{~h}$ in the extraction. Contreras-Esquivel et al. [33] reported a value of $39.05 \mathrm{mg} / 100 \mathrm{~g}$ of pectin from mango pomace using citric acid but not consider the possibility of recovering of TPMP. Similary, mango pectins' yields (5.8-24 mg/100 g) were obtained by Kratchanova et al. [47] by using an acid extraction. In this method it is necessary to use only $20 \mathrm{~min}$ for extraction and citric acid to release the pectin without compromising the stability of TPMP. For all these results it is important to remark that our proposal reflect advantages as recovering and stability of TPMP. Our proposed extraction method does not present the disadvantages of the acid extraction such as the longer extraction time and the use of a corrosive and pollutant extractant solution.

Polyphenols content (hydrolysable tannins) in the TPMP varied from 137 to $509 \mathrm{mg}$ GAE/g TPMP. Using the 1.1 method the content was significantly higher. This variability may be ascribed to factors such as soils conditions, exposition to UV radiation, ripening state and phytosanitary status. Furthermore, storage conditions may also affect polyphenol contents [1]. However, to prevent enzymatic pectin degradation and microbial spoilage of the peels they were scalded immediately after being separated from the mango. Phenolic compounds are known to be heat-sensitive. Therefore, the impact of time-temperature regime during the extraction process plays an important role in the contents of phenolic compounds. Earlier, Larrauri et al. [9] reported the total polyphenols content in aqueous methanol extract of ripe peel of Hayden variety to be $70 \mathrm{mg} / \mathrm{g}$. These values are low compared with the reported in the present study. Berardini et al. [1] reported amounts of TPMP from $71 \mathrm{mg} / 100$. These results are similar with those of our study and corroborate the high potential use of mango peels as a source of pectin and bioactive compounds. This behaviour may due to the fact that a large percentage of phenolic compounds are bound to cellular structures and time, temperature and the presence of an acid release bound phytochemicals from the matrix thus making them more accessible during extraction [48].

\section{Antioxidant Capacity of TPMP}

\section{$\mathrm{ABTS}^{+}$(ASC) and DPPH-Scavenging Capacity (DSC)}

The ABTS assay is commonly applied to determine antioxidant activity in plants. It is based on the ability of antioxidants to scavenge the long-life radical cation ABTS ${ }^{+}$. $\mathrm{DPPH}$, a stable free radical, decreases significantly on exposure to proton radical scavengers. This assay is used to evaluate the free radical scavenging activity in foods and biological systems [49]. It has also been used to evaluate the free radical scavenging activity of natural antioxidants [50]. The degree of discoloration indicates the scavenging potential of the antioxidant extract, which is due to the hydrogen donating ability [51].

Depending of the extraction method of TPMP the quantity to inhibit the reaction of oxidation was significantly different (Fig. 2). The ASC of TPMP varied from $34.61 \pm 2.23$ to $58.62 \pm 2.47$ for $\mathrm{MIC}_{50}$. The highest ASC was found for the 1.1 extraction method, this effect is due to the highest content of hydrolysable tannins. The mango peels had higher DSC ranging from $60.96 \pm 2.64$ to $99.15 \pm 13.20 \mathrm{ppm}$ of polyphenols to inhibit in a 50\% the DPPH free radical $\left(\mathrm{MIC}_{50}\right)$. The 1.1 extraction method best preserved the antioxidant properties, whereas the 3.2 extraction method was found to exert the most negative effect. Statistical analysis revealed that the antioxidant capacity in the polyphenols from mango peels changed significantly with the extraction techniques employed $(p \leq 0.05)$.

Kim et al. [25] reported $67.49 \%$ of inhibition using a concentrated ethanolic extract at $200 \mathrm{ppm}$ for ASC and $6.67 \%$ of inhibition at $25 \mathrm{ppm}$ for DSC assay. The reduced levels on phenolic compounds found in the TPMP (extraction method

Table 1 Yield and chemical analysis of TPMP

\begin{tabular}{lcrrrrr}
\hline Parameters & \multicolumn{1}{l}{ Treatment } & & & \\
\cline { 2 - 7 } & 1.1 & 1.2 & 2.1 & 2.2 & 3.1 & 3.2 \\
\hline Pectin yield (g/100 g dry peel) & $5.20 \pm 0.16^{\mathrm{d}}$ & $7.05 \pm 0.31^{\mathrm{d}}$ & $3.33 \pm 1.43^{\mathrm{e}}$ & $9.38 \pm 0.73^{\mathrm{c}}$ & $11.68 \pm 0.71^{\mathrm{b}}$ & $16.01 \pm 1.82^{\mathrm{a}}$ \\
Yield (mg TPMP/g dry peel) & $25.01 \pm 1.55^{\mathrm{c}}$ & $21.25 \pm 0.74^{\mathrm{c}}$ & $72.93 \pm 6.07^{\mathrm{b}}$ & $72.61 \pm 14.5^{\mathrm{b}}$ & $125.47 \pm 2.37^{\mathrm{a}}$ & $136.64 \pm 18.84^{\mathrm{a}}$ \\
Total sugars (mg/g TPMP) & $147.91 \pm 32.86^{\mathrm{b}}$ & $109.75 \pm 9.50^{\mathrm{b}}$ & $134.58 \pm 20.13^{\mathrm{b}}$ & $142.75 \pm 10.11^{\mathrm{b}}$ & $112.58 \pm 34.93^{\mathrm{b}}$ & $252.58 \pm 2.75^{\mathrm{a}}$ \\
Hydrolysable tannins (mg GAE/g & $509.07 \pm 9.39^{\mathrm{a}}$ & $323.07 \pm 16.59^{\mathrm{c}}$ & $495.03 \pm 12.60^{\mathrm{a}}$ & $427.06 \pm 17.68^{\mathrm{b}}$ & $296.58 \pm 4.83^{\mathrm{d}}$ & $137.15 \pm 3.19^{\mathrm{e}}$ \\
$\quad$ TPMP) & & & & & & \\
Condensed tannins (mg CE/g TPMP) & $92.39 \pm 0.78^{\mathrm{b}}$ & $92.94 \pm 1.36^{\mathrm{b}}$ & $106.27 \pm 1.36^{\mathrm{a}}$ & $108.78 \pm 1.86^{\mathrm{a}}$ & $83.78 \pm 3.81^{\mathrm{c}}$ & $107.94 \pm 5.44^{\mathrm{a}}$ \\
\hline
\end{tabular}

Different lower-case letters represent significant statistical differences among treatments (mean values) 


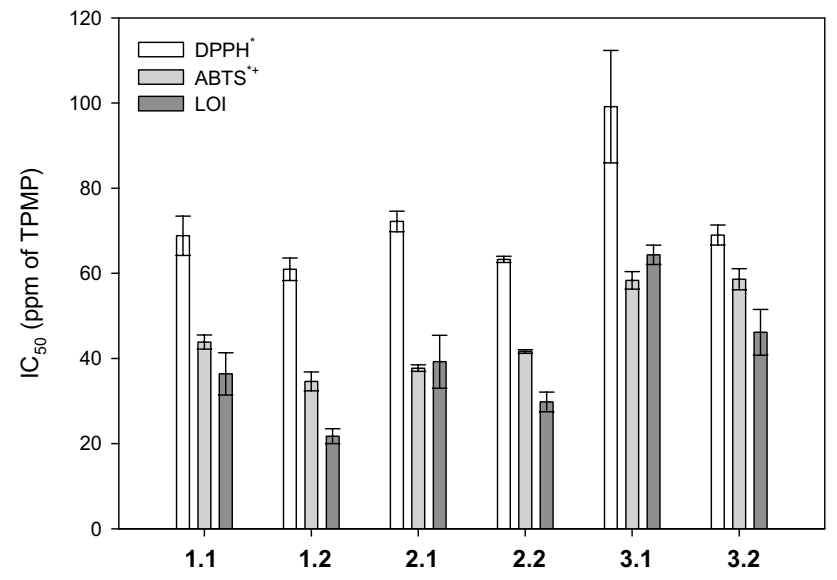

Fig. 2 Minimum inhibition concentration $\left(\mathrm{MIC}_{50}\right)$ of TPMP of all extraction methods

3.1 and 3.2) obtained from highest times and temperatures of extraction is correlated well to the ASC resulted from the degradation of phenolic compounds at high temperature and the use of citric acid, due to chemical or thermal decomposition [48]. Similar behaviour was reported by Larrauri et al. [10] observing that the drying temperature increased $\left(140{ }^{\circ} \mathrm{C}\right)$ a decrease up to $50 \%$ of the antioxidant capacity of the samples was registered. Another possible explanation is that the polyphenols in an intermediate state of oxidation can exhibit higher radical scavenging efficiency than the nonoxidized ones, although, a subsequent loss in the antioxidant properties have been found for advanced enzymatic oxidation steps $[29,48]$.

\section{Lipid Oxidation Inhibition Assay (LOI)}

Although DPPH and ABTS analysis are widely used for measuring in vitro free radical scavenging of extracts from several plants samples, they can provide only limited information about the antioxidant properties of these extracts in real biological systems. Therefore, an additional assay should be carried out to simulate the oxidization conditions in food systems. According to Huang et al. [52], the use of linoleic acid as a lipid source in the LOI assay simulates the lipids presents in food systems. Figure 2 shows the results for LOI of each extraction method. The results indicate that to inhibit the reaction of LOI in 50\% it is only necessary the use of TPMP in a range of $21.74 \pm 1.74$ (1.1 extraction method) to $64.34 \pm 2.26 \mathrm{ppm}$ (3.2 extraction method). This result is consistent with the total content of polyphenols and related with the extraction method. Dorta et al. [29] reported that the use of elevated temperatures of drying of extract diminishes the antioxidant capacity resulting in the degradation of phenolic compounds, while the presence of air leads to phytochemical compounds oxidation. We can assume that

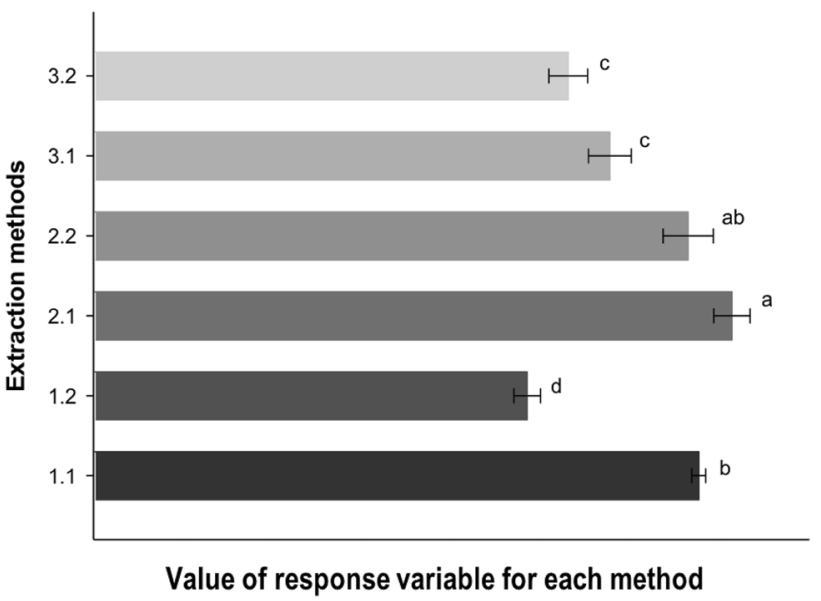

Fig. 3 Selection index

the phenolic compounds in the analyzed samples are capable of resisting linoleic acid peroxidation under assay conditions, however it is important to consider the presence of a big quantity of phenolic compounds in the samples that are capable of resisting lipid oxidation.

\section{Selection Index}

The weighting of the response variables according to their importance was necessary for the next steps of this study (electrochemical and antifungal assay). The best treatment was 2.2 due to the higher recovery of pectin, TPMP, hydrolysable tannins and higher antioxidant and antiradical activities (Fig. 3).

\section{Electrochemical Assay}

The antioxidant activity of natural compounds depends not only on the amount of specific molecules present in the matrix but also on structural factors, such as the number and positions of phenolic hydroxyl or methoxyl groups, etc [53]. Considering that the electrochemical behaviour of these compounds depends on their structural features, useful information on their antioxidant functionality can be drawn. For this purpose differential pulse voltammetry (VDP) experiments for each analyte of interest (gallic acid and quercetin) were performed. These compounds were chosen on the basis of the data reported in literature about their presence in mango under study. Figure 4 shows differential pulse voltammograms of the extract and the standards.

These results indicate the possible presence of gallic acid and quercetin in the sample. Figure 5 shows deconvolution of the differential pulse voltammogram of the behaviour of selected method (2.2) at $39.23 \mathrm{ppm}$. To verify how many peaks generate the signal, the deconvolution of 


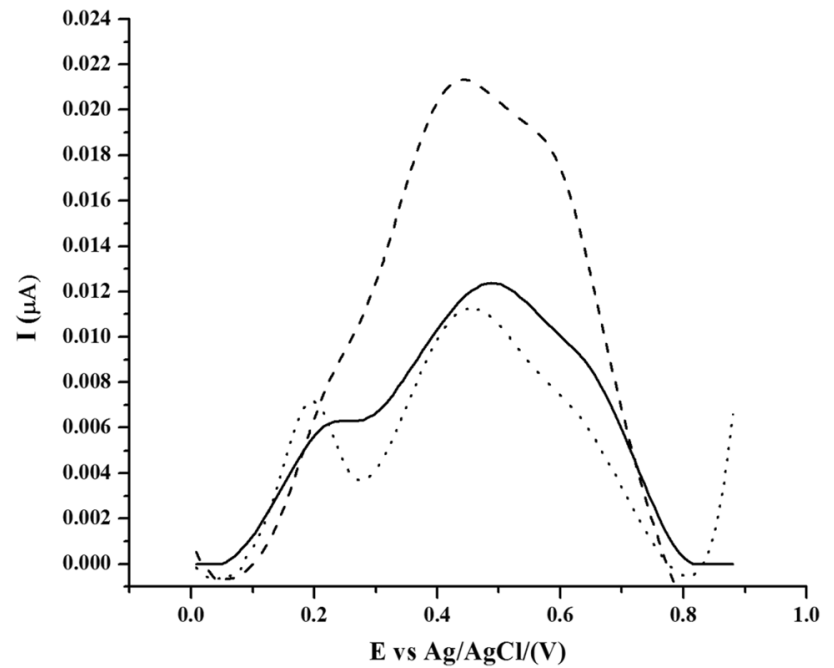

Fig. 4 Differential pulse voltammetry of extract 39.23 ppm (lines), quercetin $33.61 \mathrm{ppm}$ (dotted lines) and gallic acid $105.28 \mathrm{ppm}$ (short dashed lines)

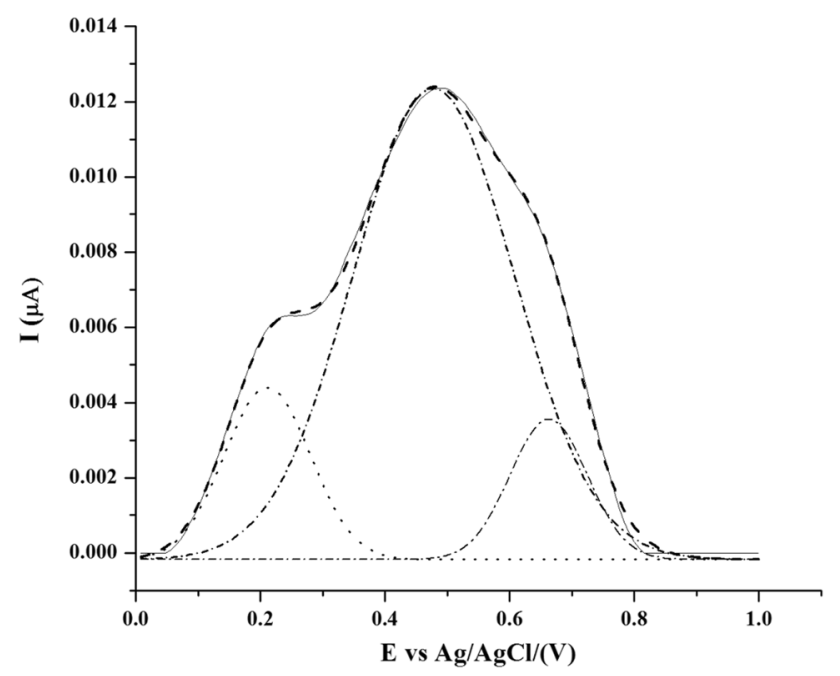

Fig. 5 Deconvolution of the differential pulse voltammogram of an extract at $29.23 \mathrm{ppm}$ : experimental (lines), calculated (short dashed lines), peak 1 (dotted lines), peak 2 (short dash dots) and peak 3 (dash dots)

differential pulse voltammogram of the extract was carried out. As shown in Fig. 5 the magnitude of the current recorded during the oxidation of the extract is generated by three independent oxidative processes with potentials $0.2,0.5$ and $0.47 \mathrm{mV}$. This is sufficient to ensure the presence of quercetin and gallic acid in the extract because the oxidation of these molecules goes on between 0.45 and $0.2 \mathrm{mV}$ and $0.5 \mathrm{mV}$ for quercetin and gallic acid, respectively. This does not discard the presence of other compounds such as mangiferin, isomangiferin, mangiferin

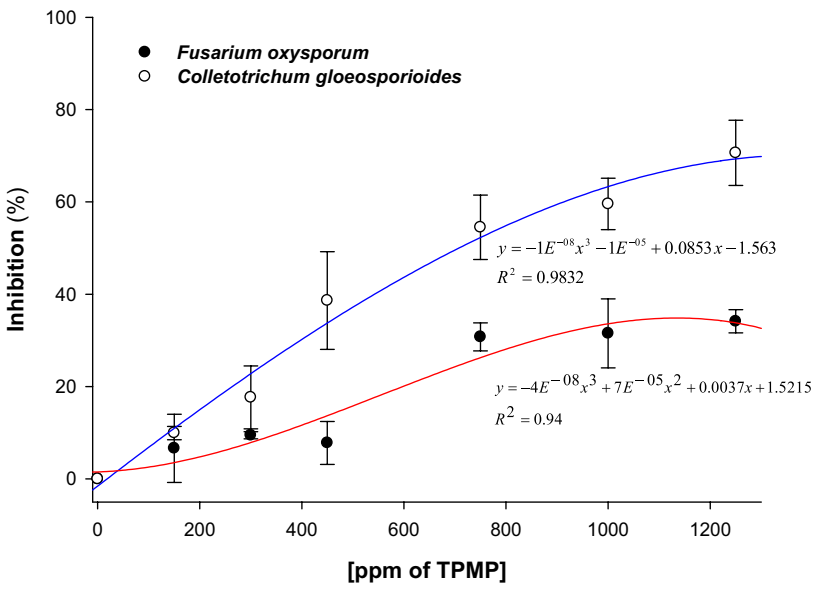

Fig. 6 Minimum inhibition concentration $\left(\mathrm{MIC}_{50}\right)$ of TPMP selected (2.2 extraction method) against Fusarium oxysporum (filled circles) and Colletotrichum gloeosporioides (open circles)

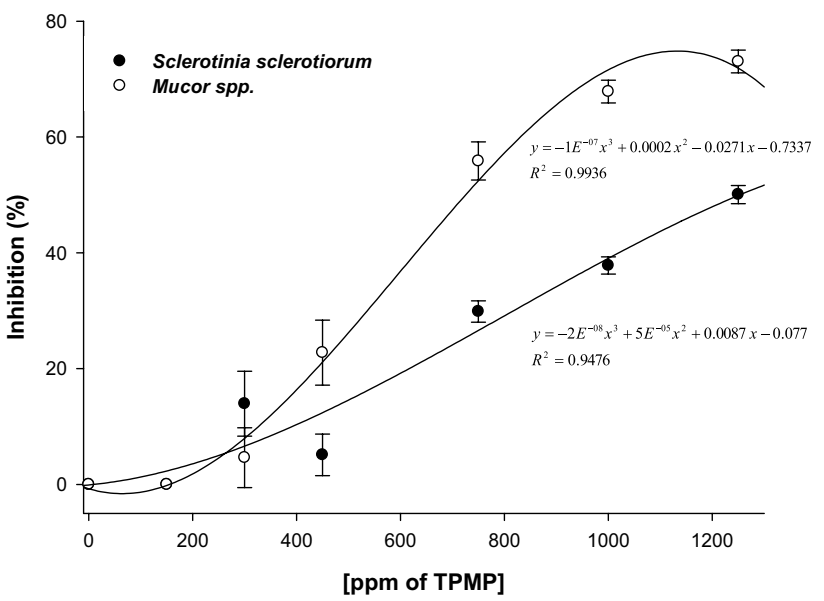

Fig. 7 Minimum inhibition concentration $\left(\mathrm{MIC}_{50}\right)$ of TPMP selected (2.2 extraction method) against S. sclerotiorum (filled circles) and Mucor sp. (open circles)

gallate, isomangiferin gallate, kaempferol 3-o-glucoside, rhamnetin 3-o-galactoside/glucoside and ellagic acid [1, $21,25]$.

\section{Antifungal Assay}

Figures 6 and 7 show $\mathrm{MIC}_{50}$ of antifungal activity of TPMP. Many researchers have reported antifungal activities of different plant species and stressed the importance of plants as a possible source of natural fungicides [54-58]. The quantity of TPMP to inhibit in 50\% the radial growth was 703.239 ppm to $C$. gloeosporioides $(\mathrm{r}=0.983), 757.178 \mathrm{ppm}$ to Mucor sp. $(\mathrm{r}=0.993), 1275.70 \mathrm{ppm}$ to $S$. sclerotiorum $(\mathrm{r}=0.947)$ and $930.07 \mathrm{ppm}$ to Fusarium oxysporum (to inhibit in $33.33 \%$ the radial growth) using the TPMP from 
selected method (2.2). In the case of $F$. oxysporum it was necessary to increase the concentration of TPMP due to the specie's antifungal resistance. The antifungal properties of TPMP have been attributed to various modes of action, in particular to their ability to interact with proteins and to inhibit enzyme activity [59, 60]. Furthermore, hydrolysable tannins were shown to damage lipid bilayer membranes allowing the release of intracellular components [61]. A third mode of action by which hydrolysable tannins may inhibit the fungal growth is related to the complexation of metal ions [62-64]. Other authors reported similar results using essential oil of Lippia berliandieri against $F$. oxysporum [65]. Soylu et al. [66] too reported that the essential oil of $O$. syriacum var. bavanii showed stronger antifungal activity against the mycelial growth of $S$. sclerotiorum under in vitro conditions. Ogbebor and Adekunle [57] reported $100 \%$ of inhibition of mycelial growth of $C$. gloeosporioides using extracts from $A$. sativum and $O$. basilicum and three other plants, A. conyzoides, J. curcas and V. amygdalina inhibit the mycelial growth in $56.83 \%, 49.90 \%$ and $48.32 \%$, respectively. These results demonstrated that this TPMP create an inappropriate environment for the growth of Colletotrichum gloeosporioides, S. sclerotiorum, Mucor $\mathrm{sp}$. and Fusarium oxysporum. Additionally, and complementing the technological development for valorisation of mango peels reported previously by Rojas et al. [67], TPMP have an enormous antifungal potential replacing chemical fungicides and which may be used for formulating new, safer and eco-friendly fungicides.

\section{Conclusions}

Six evaluated methods were highly suitable for the combined recovery of phenolic compounds and pectin from mango peels and may be integrated in the bioactive compounds production. Due to the high percentage of the bioactive compounds that was degraded during the extraction of the peels, more investigations into the optimization of the extraction parameters are necessary to improve the yield of polyphenols and pectin. Finally, investigations need to be directed at the use of TPMP as natural antioxidant and antifungal additives into the food or feed supplements.

Acknowledgements Authors thank Mexican Council for Science and Technology (CONACYT) for the financial support given to the project.

\section{References}

1. Berardini, N., Fezer, R., Conrad, J., Beifuss, U., Carl, R., Schieber, A.: Screening of mango (Mangifera indica L.) cultivars for their contents of flavonol O- and xanthone $\mathrm{C}$-glycosides, anthocyanins, and pectin. J. Agric. Food Chem. 53, 1563-1570 (2005). https:// doi.org/10.1021/jf0484069

2. Arogba, S.S.: Quality characteristics of a model biscuit containing processed mango (Mangifera indica) kernel flour. Int. J. Food Prop. 5, 249-260 (2002). https://doi.org/10.1081/JFP-120005783

3. Kaur, M., Singh, N., Sandhu, K.S., Guraya, H.S.: Physicochemical, morphological, thermal and rheological properties of starches separated from kernels of some Indian mango cultivars (Mangifera indica L.). Food Chem. 85, 131-140 (2004). https ://doi.org/10.1016/j.foodchem.2003.06.013

4. Moharram, Y.G., Moustafa, A.M.: Utilisation of mango seed kernel (Mangifera indica) as a source of oil. Food Chem. 8, 269-276 (1982). https://doi.org/10.1016/0308-8146(82)90029 $-2$

5. Puravankara, D., Boghra, V., Sharma, R.S., 2000. Effect of antioxidant principles isolated from mango (Mangifera indica L.) seed kernels on oxidative stability of buffalo ghee (butter-fat). J. Sci. Food Agric. 80, 522-526. https://doi.org/10.1002/(SICI)10970010(200003)80:4\%3C522::AID-JSFA560\%3E3.0.CO;2-R

6. Ravindran, V., Sivakanesan, R.: The nutritive value of mango seed kernels for starting chicks. J. Sci. Food Agric. 71, 245-250 (1996) https://doi.org/10.1002/(SICI)1097-0010(199606)71:2\%3C245 ::AID-JSFA578\%3E3.0.CO;2-C

7. Madhukara, K., Nand, K., Raju, N.R., Srilatha, H.R.: Ensilage of mango peel for methane generation. Process Biochem. 28, 119-123 (1993). https://doi.org/10.1016/0032-9592(93)80017-B

8. Mahadevaswamy, M., Venkataraman, L.V.: Integrated utilization of fruit-processing wastes for biogas and fish production. Biol. Wastes 32, 243-251 (1990). https://doi.org/10.1016/02697483(90)90056-X

9. Larrauri, J.A., Goñi, I., Martín-Carrón, N., Rupérez, P., SauraCalixto, F.: Measurement of health-promoting properties in fruit dietary fibres: antioxidant capacity, fermentability and glucose retardation index. J. Sci. Food Agric. 71, 515-519 (1996). https ://doi.org/10.1002/(SICI)1097-0010(199608)71:4\%3C515::AIDJSFA611\%3E3.0.CO;2-Y

10. Larrauri, J.A., Rupérez, P., Saura-Calixto, F.: Mango peels fibres with antioxidant activity. Z. Lebensm. Unters Forsch. A 205, 39-42 (1997). https://doi.org/10.1007/s002170050120

11. Larrauri, J.A., Rupérez, P., Borroto, B., Saura-Calixto, F.: Mango peels as a new tropical fibre: preparation and characterization. LWT-Food Sci. Technol. 29, 729-733 (1996). https://doi. org/10.1006/fstl.1996.0113

12. Beerh, O.P., Raghuramaiah, B., Krishnamurthy, G.V.: Utilization of mango waste: peel as a source of pectin. J. Food Sci. Technol. 13, 96-97 (1976)

13. Pedroza-Islas, R., Aguilar-Esperanza, E.: 1994. Obtaining pectins from solid wastes derived from mango (Mangifera indica) processing. AIChE Symp. Ser. 300, 36-41

14. Srirangarajan, A.N., Shrikhande, A.J.: Mango peel waste as a source of pectin. Curr. Sci. 45, 620-621 (1976)

15. Tandon, D.K., Garg, N.: Mango waste: a potential source of pectin, fiber, and starch. Indian J. Environ. Prot. 19, 924-927 (1999)

16. Tandon, D.K., Kalrat, S.K., Singh, B.P., Garg, N.: Characterization of pectin from mango fruit waste. Indian Food Packer 45, 9-12 (1991)

17. Schieber, A., Berardini, N., Carle, R.: Identification of flavonol and xanthone glycosides from mango (Mangifera indica $\mathrm{L} . \mathrm{cv}$. F Tommy Atkins) peels by high-performance liquid chromatography-electrospray ionization mass spectrometry. J. Agric. Food Chem. 51, 5006-5011 (2003)

18. Berardini, N., Carle, R., Schieber, A.: Characterization of gallotannins and benzophenone derivatives from mango (Mangifera indica L. cv. F Tommy Atkins) peels, pulp and kernels by highperformance liquid chromatography/electrospray ionization mass 
spectrometry. Rapid Commun. Mass Spectrom. 18, 2208-2216 (2004). https://doi.org/10.1002/rcm.1611

19. Kang, D.G., Moon, M.K., Choi, D.H., Lee, J.K., Kwon, T.O., Lee, H.S.: Vasodilatory and anti-inflammatory effects of the 1,2,3,4,6-penta-O-galloyl- $\beta$-D-glucose (PGG) via a nitric oxidecGMP pathway. Eur. J. Pharmacol. 524, 111-119 (2005)

20. Ajila, C.M., Bhat, S.G., Prasada-Rao, U.J.S.: Valuable components of raw and ripe peels from two Indian mango varieties. Food Chem. 102, 1006-1011 (2007). https://doi.org/10.1016/j.foodc hem.2006.06.036

21. Ajila, C.M., Naidu, K.A., Bhat, S.G., Prasada-Rao, U.J.S.: Bioactive compounds and antioxidant potential of mango peel extract. Food Chem. 105, 982-988 (2007). https://doi.org/10.1016/j.foodc hem.2007.04.052

22. Ren, Y., Himmeldirk, K., Chen, X.: Synthesis and structureactivity relationship study of antidiabetic penta-O-galloyl-Dglucopyranose and its analogues. J. Med. Chem. 49, 2829-2837 (2006)

23. Ribeiro, S.M.R., Barbosa, L.C.A., Queiroz, J.H., Knödler, M., Schieber, A.: Phenolic compounds and antioxidant capacity of Brazilian mango (Mangifera indica L.) varieties. Food Chem. 110, 620-626 (2008). https://doi.org/10.1016/j.foodchem.2008.02.067

24. Engels, C., Knödler, M., Zhao, Y.Y., Carle, R., Gänzle, M.G., Schieber, A.: Antimicrobial activity of gallotannins isolated from mango (Mangifera indica L.) kernels. J. Agric. Food Chem. 57, 7712-7718 (2009). https://doi.org/10.1021/jf901621m

25. Kim, H., Moon, J.Y., Kim, H., Lee, D.S., Cho, M., Choy, H.K., Kim, Y.S., Mosaddik, A., Cho, S.K.: Antioxidant and antiproliferative activities of mango (Mangifera indica L.) flesh and peel. Food Chem. 121, 429-436 (2010). https://doi.org/10.1016/j.foodc hem.2009.12.060

26. Kim, M.S., Park, S.B., Suk, K., Kim, I.K., Kim, S.Y., Kim, J.A.: Gallotannin isolated from Euphorbia species, 1,2,6-tri-O-galloyl$\beta$-D-allose, decreases nitric oxide production through inhibition of nuclear factor- $\mathrm{\kappa B}$ and downstream inducible nitric oxide synthase expression in macrophages. Biol. Pharm. Bull. 32, 1053-1056 (2009)

27. Manthey, J.A., Perkins-Veazie, P.: Influences of harvested date and location on the levels of $\beta$-Carotene, ascorbic acid, total phenols, the in vitro antioxidant capacity, and phenolic profiles of five commercial varieties of mango (Mangifera indica L.). J. Agric. Food Chem. 57, 10825-10830 (2009). https://doi.org/10.1021/ jf902606h

28. Jiang, L.Y., He, S., Pan, Y.J., Sun, C.R.: Bioassay-guided isolation and EPR-assisted antioxidant evaluation of two valuable compounds from mango peels. Food Chem. 119, 1285-1292 (2010). https://doi.org/10.1016/j.foodchem.2009.09.005

29. Dorta, E., Lobo, M.G., González, M.: Using drying treatments to stabilize mango peel and seed: effect on antioxidant activity. LWT-Food Sci. Technol. 45, 261-268 (2012). https://doi. org/10.1016/j.lwt.2011.08.016

30. Ma, X., Wu, H., Liu, L., Yao, Q., Wang, S., Zhan, R., Xing, S., Zhou, Y.: Polyphenolic compounds and antioxidant properties in mango fruits. Sci. Hortic. 129, 102 (2011). https://doi. org/10.1016/j.scienta.2011.03.015 107.

31. Seeram, N., Lee, R., Herber, D.: Rapid large scale purification of ellagitannins from pomegranate husk, a byproduct of the commercial juice industry. Sep. Purif. Technol. 41, 49-55 (2005). https:// doi.org/10.1016/j.seppur.2004.04.003

32. Ascasio-Valdes, J.A., Aguilera-Carbó, A., Martínez-Hernandez, J.L., Rodríguez-Herrera, R., Aguilar, C.N.: Euphorbia antisyphilitica residues as a new source of ellagic acid. Chem. Pap. 64(4), 528-532 (2010). https://doi.org/10.2478/s11696-010-0034-6

33. Contreras-Esquivel, J.C., Espinoza-Pérez, J.D., Montanez, J.C., Charles-Rodríguez, A.V., Renovato, J., Aguilar, C.N., Wicker,
L.: Extraction and characterization of pectin from novel sources advances in biopolymers. J. Am. Chem. Soc. 935, 215-229 (2006). https://doi.org/10.1021/bk-2006-0935.ch014

34. Serna-Cock, L., García-Gonzales, E., Torres-León, C.: Agroindustrial potential of the mango peel based on its nutritional and functional properties. Food Rev. Int. 32(4), 364-376 (2016)

35. Torres-León, C., Rojas, R., Contreras-Esquivel, J.C., Serna-Cock, L., Belmares-Cerda, R.E., Aguilar, C.N.: Mango seed: functional and nutritional properties. Trends Food Sci. Technol. 55, 109-117 (2016)

36. Torres-León, C., Rojas, R., Serna-Cock, L., Belmares-Cerda, R., Aguilar, C.N.: Extraction of antioxidants from mango seed kernel: optimization assisted by microwave. Food Bioprod. Process. 105, 188-196 (2017)

37. Torres-León, C., Ventura-Sobrevilla, J., Serna-Cock, L., AscacioValdés, J.A., Contreras-Esquivel, J., Aguilar, C.N.: Pentagalloylglucose (PGG): a valuable phenolic compound with functional properties. J. Funct. Foods 37, 176-189 (2017)

38. Dubois, M., Gilles, K.A., Hamilton, J.K., Rebers, P.A., Smith, F.: Colorimetric method for determination of sugars and related substances. Anal. Chem. 28, 350-356 (1956). https://doi.org/10.1021/ ac60111a017

39. Swain, T., Hillis, W.E.: The phenolic constituents of Prunus domestica. I.- the quantitative analysis of phenolic constituents. J. Sci. Food Agric. 10(1), 63-68 (1959). https://doi.org/10.1002/ jsfa. 2740100110

40. Makkar, H.P.S.: Chemical methods, condensed and hydrolysable tannins. In: Makkar, H.P.S. (ed.) Quantification of Tannins in Tree Foliage. A Laboratory Manual, pp. 5-8. Kluwer Academic Publishers, Netherlands (2003). https://doi.org/10.1021/bk-19970662.ch012

41. Porter, L.J., Hrstich, L.N., Chan, B.G.: The conversion of procyanidins and prodelphinidins to cyanidin and delphinidin. Phytochemistry. 25, 223-230 (1986). https://doi.org/10.1016/S0031 -9422(00)94533-3

42. Molyneux, P.: The use of the stable free radical diphenylpicrylhydrazyl (DPPH) for estimating antioxidant activity. Songklanakarin J. Sci. Technol. 26(2), 211-219 (2004)

43. Re, R.,. Pellegrini, N., Proteggente, A., Pannala, A., Yang, M., Rice-Evans, C.: Antioxidant activity applying an improved ABTS radical cation decolorization assay. Free Radic. Biol. Med. 26, 1231-1237 (1999)

44. Starzynska-Janiszewska, A., Stodolak, B., Jamroz, M.: Antioxidant properties of extracts from fermented and cooked seeds of Polish cultivars of Lathyrus sativus. Food Chem. 109, 285-292 (2008). https://doi.org/10.1016/j.foodchem.2007.12.028

45. Martinez-Avila, G.C., Aguilera-Carbo, A.F., Rodriguez-Herrera, R., Aguilar, C.N.: Fungal enhancement of the antioxidant properties of grape. Ann. Microbiol. 62(3), 923-930 (2011). https://doi. org/10.1007/s13213-011-0329-z

46. Sirisakulwat, S., Nagel, A., Sruamsiri, P., Carle, R., Neidhart, S.: Yield and quality of pectins extractable from the peels of Thai mango cultivars depending on fruit ripeness. J. Agric. Food Chem. 56(22), 10727-10738 (2008)

47. Kratchanova, M., Bénémou, C., Kratchanov, C.: On the pectic substances of mango fruits. Carbohydr. Polym. 15, 271-282 (1991). https://doi.org/10.1016/0144-8617(91)90042-B

48. Nicoli, M.C., Anese, M., Parpinel, M.: Influence of processing on the antioxidant properties of fruit and vegetables. Trends Food Sci. Technol. 10(3), 94-100 (1999). https://doi.org/10.1016/S0924 -2244(99)00023-0

49. Sánchez-Moreno, C.: Methods used to evaluate the free radical scavenging activity in foods and biological systems. Food Sci. Technol. Int. 8, 121-137 (2002). https://doi.org/10.1106/10820 1302026770 
50. Singh, N., Rajini, P.S.: Free radical scavenging activity of an aqueous extract of potato peel. Food Chem. 85, 611-616 (2004). https ://doi.org/10.1016/j.foodchem.2003.07.003

51. Van Gadow, A., Joubert, E., Hannsman, C.T.: Comparison of the antioxidant activity of Aspalathin with that of other plant phenols of Rooibos Tea (Aspalathus linearis), $\alpha$-tocopherol, BHT, and BHA. J. Agric. Food Chem. 45, 632-638 (1997). https://doi. org/10.1021/jf960281n

52. Huang, D.J., Ou, B.X., Prior, R.L.: The chemistry behind antioxidant capacity assays. J. Agric. Food Chem. 53, 1841-1856 (2005). https://doi.org/10.1021/jf030723c

53. Cosio, M.S., Buratti, S., Mannino, S., Benedetti, S.: Use of an electrochemical method to evaluate the antioxidant activity of herb extracts from the Labiatae family. Food Chem. 97, 725-731 (2006). https://doi.org/10.1016/j.foodchem.2005.05.043

54. Tewari, S.N.: Ocimum sanctum L., a botanical fungicide for rice blast control. Trop. Sci. 35, 263-273 (1995)

55. Tewari, S.N., Dath, P.: Effects of some leaf media of some plants on the growth of three fungal pathogens of rice. Indian Phytopathol. 37, 458-461 (1984)

56. Lakshmanan, P.: Effect of certain plant extracts against Corynespora cassiicola. Indian J. Mycol. Plant Pathol 20(3), 267-269 (1990)

57. Ogbebor, N.O., Adekunle, A.T.: 2005. Inhibition of conidial germination and mycelial growth of Corynespora cassiicola (Berk and Curt) of rubber (Hevea brasiliensis muell. Arg.) using extracts of some plants. Afr. J. Biotechnol. 4(9), 996-1000. https://doi. org/10.4314/2Fajb.v4i9.71145

58. Philip, T., Sharma, D.D.: In vitro evaluation of Leaf and oil cake extracts of Azadirachta indica and Pongamia glabra on mulberry root rot pathogens. Indian J. Seric. 36(2), 150-152 (1997)

59. Konishi, K., Adachi, H., Ishigaki, N., Kanamura, Y., Adachi, I., Tanaka, T., Nishioka, I., Nonaka, G.I., Horikoshi, I.: Inhibitory effects of tannins on NADH dehydrogenases of various organisms. Biol. Pharm. Bull. 16, 716-718 (1993)

60. Cannell, R.J.P., Farmer, P., Walker, J.M.: Purification and characterization of pentagalloylglucose, an R-glucosidase inhibitor/ antibiotic from the freshwater green alga Spirogyra varians. Biochem. J. 255, 937-941 (1988)

61. Funatogawa, K., Hayashi, S., Shimomura, H., Yoshida, T., Hatano, T., Ito, H., Hirai, Y.: Antibacterial activity of hydrolyzable tannins derived from medicinal plants against Helicobacter pylori. Microbiol. Immunol. 48, 251-261 (2004)

62. Chung, K.T., Wei, C.I., Johnson, M.G.: Are tannins a doubleedged sword in biology and health. Trends Food Sci. Technol. 9, 168175 (1998). https://doi.org/10.1016/S0924-2244(98)00028-4

63. Scalbert, A.: Antimicrobial properties of tannins. Phytochemistry 30, 3875-3883 (1991). https://doi.org/10.1016/00319422(91)83426-L

64. Scalbert, A., Mila, I., Expert, D., Marmolle, F., Albrecht, A.M., Hurrell, R., Huneau, J.F., Tomé, D.: Polyphenols, metal ion complexation and biological consequences. In: Gross, G.G., Hemingway, R.W., Yoshida, T. (eds.) Plant Polyphenols 2: Chemistry, Biology, Pharmacology, Ecology, 1st edn., p. 545. Kluwer Academic/Plenum Publishers, New York (1999). https://doi. org/10.1007/978-1-4615-4139-4_30

65. Cueto-Wong, M.A., Rivas-Morales, C., Alanis-Guzman, M.G., Oranday-Cardenas, A., Amaya-Guerra, C.A., Nuñez-Gonzalez, A., Samaniego-Gaxiola, J.A., Cano-Rios, P.: Antifungal properties of essential oil of Mexican oregano (Lipia berliandieri) against Fusarium oxysporum f. sp. lycopersici. Rev. Mex. Micol. 31, 29-35 (2010). http://www.scielo.org.mx/scielo.php?scrip $\mathrm{t}=$ sci_arttext\&pid=S0187-31802010000100005\&lng=es.

66. Soylu, H., Yigitbas, E.M., Soylu, S.: Kurt antifungal effects of essential oils from oregano and fennel on Sclerotinia sclerotiorum. J. Appl. Microbiol. 103, 1021-1030 (2007). https://doi.org/10.11 11/j.1365-2672.2007.03310.x

67. Rojas, R., Contreras-Esquivel, J.C., Orozco-Esquivel, M.T., et al.: Mango peel as source of antioxidants and pectin: microwave assisted extraction. Waste Biomass Valoriz. 6, 1095 (2015). https ://doi.org/10.1007/s12649-015-9401-4 